\title{
Physical and Sedentary Activity during CoviDig-induced Confinement
}

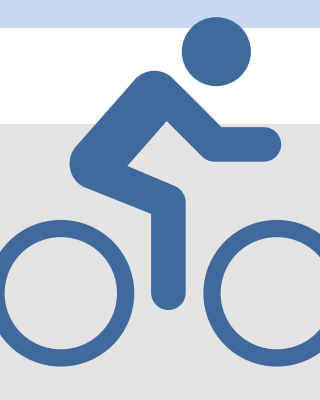

\section{Introduction}

COVID19 was declared as fatal pandemic by the WHO in March, 20.

As of Sept 20, the total is approaching 35,000,000 cases and 1,000,000 fatality (Peeri, 20).

COVID19 is a highly pathogenic virus (Bai, 20).

People are spending more time at home due to confinement measures, which affect lifestyle and health. Decreased PA and increased SA are known for deteriorated health and quality of life.

They are documented to increase the risk of diseases, hospitalization, morbidity, and mortality.

Purpose
In the current investigation:
Changes in PA activity SA during COVID19 was
investigated.
The factors that might contribute to these changes.
Design and participants
Cross-sectional survey distributed via social media
during April and May of 2020 to examine the changes
in PA and SA.
Adults (age >18 years) of both genders voluntarily
consented to the study.
Questionnaire
Domains covered in the questionnaire:
Demographics (i.e. age, gender, socioeconomic status)
lifting.
Perception and implemented confinement procedures
Changes in PA and SA during the pandemics.
secial media.

\begin{tabular}{|c|c|c|}
\hline \multicolumn{3}{|c|}{ Results } \\
\hline \multicolumn{3}{|c|}{$\begin{array}{l}\text { Table 1: } \\
\text { o 1844 individuals responded to the questionnaire. } \\
\text { o Age, weight, and height ranges were } 18-72 \text { years, } \\
38-144 \mathrm{~kg} \text {, and } 120-198 \mathrm{~cm} \text {, respectively. } \\
\text { Most of the participants were women, with a } \\
\text { bachelor degree, receiving middle income, who are } \\
\text { unemployed while more than } 50 \% \text { were either } \\
\text { overweight, obese or severely obese }\end{array}$} \\
\hline \multicolumn{3}{|c|}{ Table 1. The participant demographic ( $\mathrm{n}=1844)$} \\
\hline Gender $(\%$ & male) & 30.5 \\
\hline Age (yrs, & ean $\pm S D$ ) & $33.7 \pm 11.3$ \\
\hline Weigh & $\mathrm{SD})$ & $72.6 \pm 16.3$ \\
\hline \multirow{2}{*}{\multicolumn{3}{|c|}{ Obesity (BMI; \%) }} \\
\hline & & \\
\hline & Under weight & \\
\hline & Norma & 43.3 \\
\hline & Overwei & 35.4 \\
\hline & Obese & 14.8 \\
\hline & Overly obese & 4. \\
\hline \multicolumn{3}{|c|}{ Level of Education (\%) } \\
\hline & High school and less & 19.4 \\
\hline & Associate degree & 14.1 \\
\hline & Bach & 51.3 \\
\hline & Graduate degree & 15. \\
\hline \multicolumn{3}{|c|}{ Income (\%) } \\
\hline & Low & 34.5 \\
\hline & Middle & 65.5 \\
\hline & High & \\
\hline \multicolumn{3}{|l|}{ Job type } \\
\hline & Unemployed/retired & $\begin{array}{r}35.6 \\
4.8\end{array}$ \\
\hline & Edu & $\begin{aligned} 4.0 & \\
23.9 & \end{aligned}$ \\
\hline & Agriculture & \\
\hline & Health & 14.0 \\
\hline & Manufacturing & \\
\hline & Engineeri & 5.8 \\
\hline & Man & 8.2 \\
\hline & Crafting & 3.2 \\
\hline
\end{tabular}
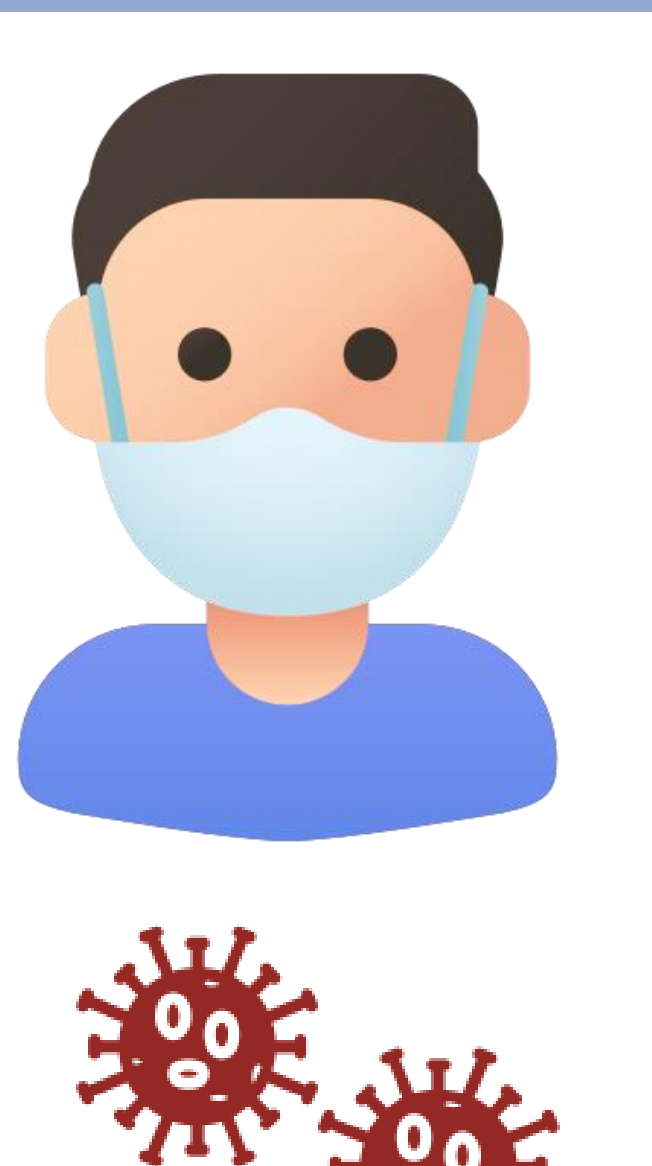

列

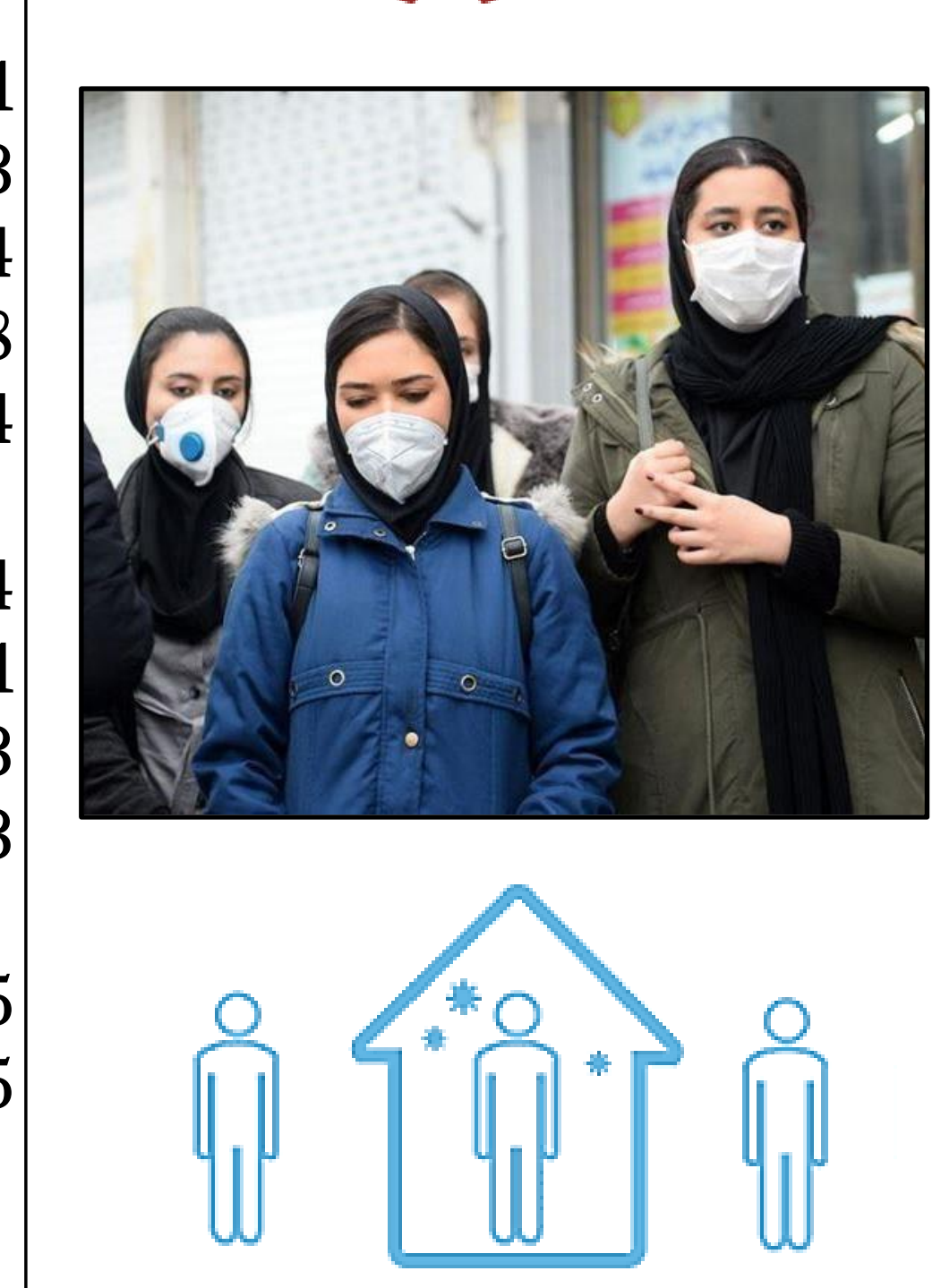

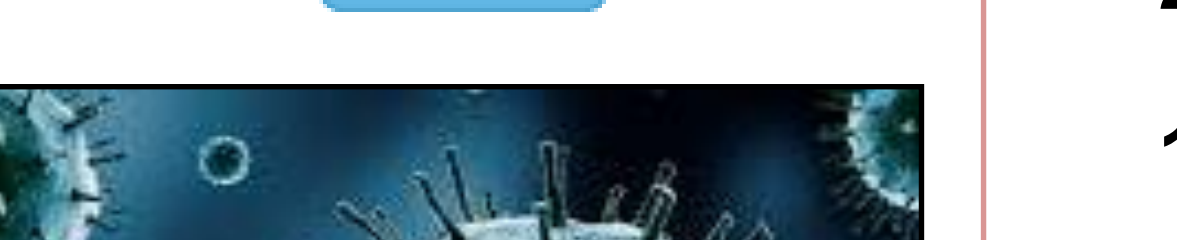
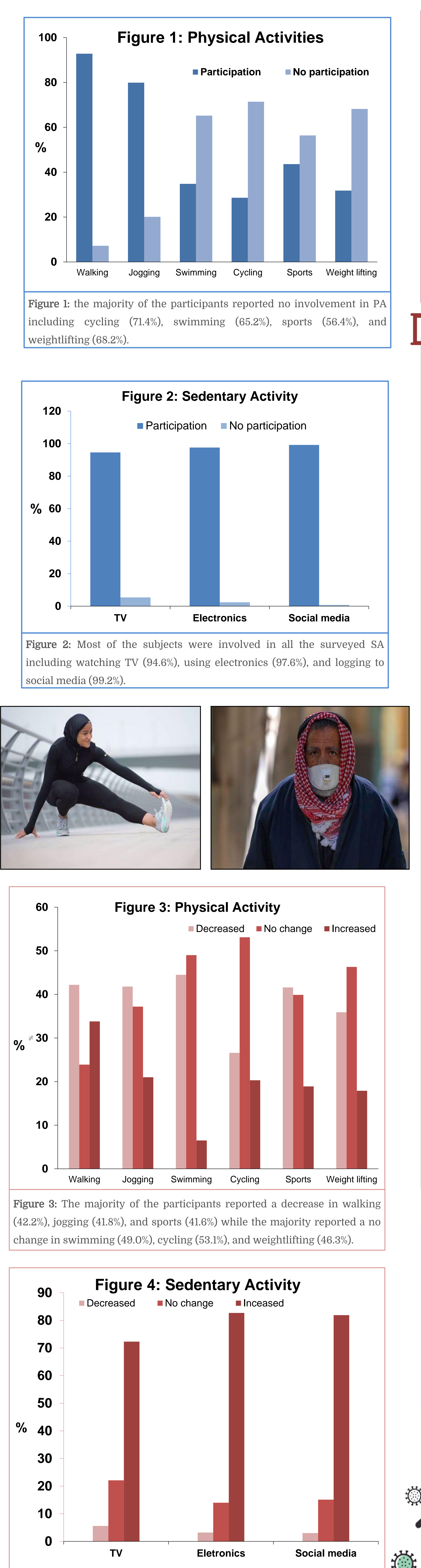

Figure 4: Most of the participants reported an increase in SA including watching TV $(72.3 \%)$, using electronics $(82.7 \%)$, and logging $(81.9 \%)$ to socia

\section{Main Findings}

The current study revealed a $35.9-44.5 \%$ decrease in the different modes of PAs and $72.1 \%-82.7 \%$ increase in the various $\mathrm{SA}$ measures.

Age, gender, income, occupation, obesity, and being worried about conducting COVID19 are associated with the changes in PA and SA.

il

\section{Discussion and Conclusions}

As previously has been anticipated (Carter, 20; Narici, 20), PA and SA decreased and increased, respectively among the participants in the current study during confinement due to COVID19.

The ramifications of these changes remained to be unraveled, however these results are alarming and might be associated with adverse health effects.

Reduced PA and increased SA may impact all body systems including metabolic, respiratory, cardiovascular, musculoskeletal, and immune systems (Carter, 20; Narici, 20).

Age, gender, income, occupation, obesity, and being worried about conducting COVID19 seem to predict changes in PA and SA.

Therefore, strategies are needed to help people staying active to mitigate the possible adverse health effects during the current and future pandemic-induced confinements.

These strategies should consider the demographics and socioeconomic status factors when implemented.

\section{Recommendations}

tudies are needed to verify the current findings. Additionally, strategies are warranted to encourage people staying active and to mitigate the adverse health effects of inactivity due to confinement during the current and future pandemics.

\section{References} था

(Peeri et al., 2020; Rothan \& Byrareddy, 2020) (Z. Bai et al., 2020; Calton, Abedini, \& Fratkin, 2020) (Gane, Kelly, \& Hopkins, 2020; Verity et al., 2020). Elfiky, 2020; Joynt \& Wu, 2020).

(i.e. educational, medical, versus managerial), (Carter et al., 2020; Chen et al., 2020; Jurak et al., 2020; Narici et al., 2020; Pecanha et al., 2020; Rahmati-Ahmadabad \& Hosseini, 2020 